\title{
LABORATORY MEDICINE
}

\section{Laboratory instruments for the physician's office laboratory: Technology and cost-benefits}

\author{
WALTER C. HOOK, MT(ASCP), MS \\ JOHN J. FERNANDES, DO
}

During the past two decades, medicine has witnessed the decentralization of laboratory testing from the hospital into the physician's office. This article focuses on the technical aspects of the instruments now available for laboratory testing in the physician's office. Consideration is given to specific instruments, methods, and cost-benefit.

(Key words: Instruments, office laboratory, cost-benefit, technology)

The decentralization of laboratory testing away from the hospital and into physicians' offices during the past 20 years may be attributed to several factors. Patient benefit predominantly explains the increased number of laboratory tests being performed in physicians' offices. Most advocates of physicians' office laboratories (POLs) emphasize that results are available more quickly, and patient anxiety

From the Department of Pathology and Laboratory Medicine, Philadelphia College of Osteopathic Medicine, Philadelphia, $\mathrm{Pa}$, where $\mathrm{Mr}$ Hook is acting administrative director of laboratories, Dr Fernandes is professor of pathology, Chicago College of Osteopathic Medicine, Downers Grove, Ill.

The authors have no commercial or proprietary interest in the instruments discussed nor do they have any financial interest (as consultant, reviewer, or evaluator) in the instruments. Furthermore, specific identification of instrument manufacturers and models does not constitute endorsement by the authors.

Reprint requests to John J. Fernandes, DO, Department of Pathology, Olympia Fields Osteopathic Hospital and Medical Center, 20201 Crawford Ave, Olympia Fields, IL 60461. is reduced when laboratory tests are performed at the time of the office visit. In many instances, patients lose less time from work because ready availability of test results allows the physician to begin therapy sooner.

Financial reimbursement for laboratory testing by third-party carriers is another incentive for many physicians to have POLs. This reimbursement can be substantial if the physician selects cost-effective instruments, and judiciously complies with appropriate state and federal regulatory agencies.

However, patient benefit and financial factors were only the catalysts for the development of instrumentation for POLs. The development of the microprocessor-a general-purpose digital computer on a single, integratedcircuit chip - most significantly facilitated the decentralization of laboratory testing. Microprocessors have led to a reduction in the size of the instruments used in the hospital laboratory while enhancing the capabilities of those instruments. Microprocessors have been used to control the movement of samples and reagents within automated instruments, to convert optical readings to numeric test results, and to collate patient test results. Reduction in instrument size with added automation has enabled the easy operation of laboratory instruments - frequently by nontechnical personnel-away from the specialized environments found in hospitals.

The typical laboratory instruments used in POLs can be classified in one of three general 
Table 1

Clinical Chemistry Analyzers for the Physician's Office Laboratory

\begin{tabular}{|c|c|c|c|c|}
\hline Manufacturer & Model & Type & Comments & Cost \\
\hline $\begin{array}{l}\text { Abbott Laboratories } \\
\text { Diagnostics Division }\end{array}$ & Vision & $\begin{array}{l}\text { Bench-top } \\
\text { Semi-automated }\end{array}$ & Proprietary reagents & $\$ 20,000^{*}$ \\
\hline $\begin{array}{l}\text { Abbott Park 605th D-49B } \\
\text { Abbott Park, ㅍ 60064 } \\
1 \text { (800) } 323-9100\end{array}$ & Spectrum & Automated & $\begin{array}{l}290 \text { samples per hour } \\
\text { Requires water hookup }\end{array}$ & $\$ 90,000$ \\
\hline $\begin{array}{l}\text { Du Pont Company } \\
\text { Medical Products Dept } \\
\text { Wilmington, DE } 19898 \\
1(800) 527-2601\end{array}$ & Analyst & Bench-top & $\begin{array}{l}\text { Proprietary reagents } \\
12 \text { test panels per } 10 \mathrm{~min} \\
12 \text { routine tests } \\
\text { plus theophylline }\end{array}$ & $\$ 15,000^{*}$ \\
\hline $\begin{array}{l}\text { Eastman Kodak Company } \\
343 \text { State St } \\
\text { Rochester, NY } 14650 \\
1(800) 445-6325 \text { EXT } 434\end{array}$ & DT System & Bench-top & $\begin{array}{l}\text { Proprietary reagents } \\
27 \text { routine tests } \\
\text { Electrolyte and special } \\
\text { chemistry modules }\end{array}$ & $\$ 7,000^{*}$ \\
\hline $\begin{array}{l}\text { Roche Diagnostic System, Inc } \\
\text { Subsidiary of Hoffman- } \\
\text { La Roche, Inc } \\
\text { Montclair, NJ } 07042 \\
1(800) 526-1247\end{array}$ & Cobas Mira & Bench-top & $\begin{array}{l}\text { Open reagent system } \\
35+\text { assays available } \\
132 \text { to } 204 \text { tests per hour }\end{array}$ & $\$ 30,000^{*}$ \\
\hline
\end{tabular}

categories based on function: routine chemistry analyzers, immunochemistry analyzers, and cell counters.

\section{Chemistry analyzers}

The instruments used to perform routine chemistry studies vary in size, degree of sophistication, and price. Table 1 lists chemistry analyzer manufacturers, respresentative models that can be used in POLs, and a brief description of each instrument.

Depending on the size of the POL and the physician's type of practice (solo or group), the instrument selection can vary from a benchtop analyzer, such as the Eastman Kodak DT system at a cost of approximately $\$ 6000$ to $\$ 8000$, depending on ancillary devices obtained with the instrument and the physician's negotiating skills, up to the Abbott Spectrum, which costs approximately $\$ 90,000$ and can perform more than 18 tests on 290 specimens per hour.

Midsize analyzers are available that combine the advantages of higher throughput with reduced analyzer size. The midsize analyzers have basically the same test menu as the larger analyzers; however, their base prices are approximately a third the cost of the larger analyzers.

Basic chemistry analyzers differ in size, degree of automation, data reduction capabilities, and analytic speed. The smaller benchtop analyzers generally consist of a manually operated instrument that uses dry reagent that must be reconstituted before use. All specimen and reagent handling must be done by the operator. Another difference among the instruments to be considered is the test menu. The DT system, unlike other instruments in its class, has a large test menu that consists of the most commonly ordered tests, plus electrolyte measurements and enzyme assays.

The basic menu on any routine chemistry analyzer consists of glucose, urea nitrogen, creatinine, cholesterol, high-density-lipoprotein cholesterol, electrolytes (provided by an electrolyte analyzer module), and a limited number of enzyme assays that include aspartate and alanine aminotransferases, creatine kinase (CK), and lactate dehydrogenase $(\mathrm{LDH})$. Midsize analyzers such as the Roche Cobas Mira and large chemistry analyzers 
such as the Abbott Spectrum have expanded test menus that include more than 35 tests. The additional tests include bilirubin, calcium, magnesium, $\mathrm{LDH}$ isoenzymes, $\mathrm{CK}$ isoenzymes, and therapeutic drug monitoring (for example, theophylline and digoxin).

If the instrument has an "open reagent system," any photometric assay can be performed. This feature does not exist on the small benchtop analyzers, such as the Eastman Kodak DT system or the Du Pont Analyst instruments, which require reagents that are sold only by the instrument's manufacturer in a configuration that fits exclusively on that manufacturer's equipment. Therefore, the user is restricted from obtaining reagents and supplies from nonproprietary sources, and is locked into performing only those tests for which the manufacturer has prepackaged reagents. Because the majority of midsize routine chemistry analyzers have open reagent systems, nonproprietary reagents can be purchased from vendors other than the instrument's manufacturer.

Small bench-top instruments have microprocessors that control the photo-optical system, convert the optical reading to a numeric test value, and collate test results by correctly matching the patient identification with the appropriate test result. However, sample throughput is reduced because specimen and reagent handling is performed manually by the operator. The sample throughput on the Eastman Kodak DT-60 averages approximately 45 to 50 tests per hour.

Midsize bench-top analyzers have automated reagent and specimen handling, and have significantly enhanced data-reduction capabilities. Because of these features, the midsize analyzers have a higher test throughput. For example, the Cobas Mira can perform 132 tests per hour (204 tests per hour with an optional ion selective electrode system for electrolyte measurements). The Abbott Spectrum has automated specimen and reagent handling, faster specimen throughput (approximately 290 specimens per hour), and sophisticated data handling. (The data processing capabilities of the instrument are comparable to those available on any personal computer.)

Although the differences among the three sizes of chemistry analyzers are quite obvious, the important consideration for the primary care physician is directed at the selection of a system that is optimal for the patient mix. More is not always better if the physician wishes to perform only glucose and cholesterol screening of a limited patient population. However, in a large group practice, the financial incentives may favor either the purchase or the lease/rental of a larger chemistry analyzer. The choice of a chemistry analyzer is always volume-driven.

\section{Immunochemistry analyzers}

Immunochemistry analyzers are another class of instruments used in POLs. Table 2 lists immunochemistry analyzer manufacturers, representative models, and a brief description of the units. Immunochemistry analyzers are bench-top instruments, similar to basic chemistry analyzers in that they use an optical system to measure the reaction of specimen with reagent.

The photo-optical detection systems of immunochemistry analyzers for POLs use test nonisotopic immunochemical methods based on either fluorescence or turbidimetry to quantify analytes in patient samples. The Abbott TDx uses fluorescence polarization immunoassays (FPIA) in which a plane of polarized light is used to fluoresce the sample-reagent mixture. By measuring polarized fluorescence, interference from extraneous fluorescent substances that may be found in the blood is virtually eliminated. By combining fluorescence with either dry-film immunoassays and enzyme-linked immunosorbent assays (ELISAs), the PB Diagnostics Opus can optimally quantify analytes in patient samples. For example, theophylline is quantified by using a dry-film technique in which the patient's serum sample is added to dry film that contains a fluorescent-labeled hapten bound to an antibody. The analyte in the patient's sample competes with the fluorescent labeled hapten for binding sites on the antibody to that hapten and analyte. The amount of fluorescence is proportional to the concentration of the analyte in the patient sample.

The Opus can be used to quantify digoxin (continued on page 885) 


\section{\#1 THERAPY FOR ROSACEA}

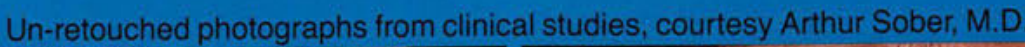

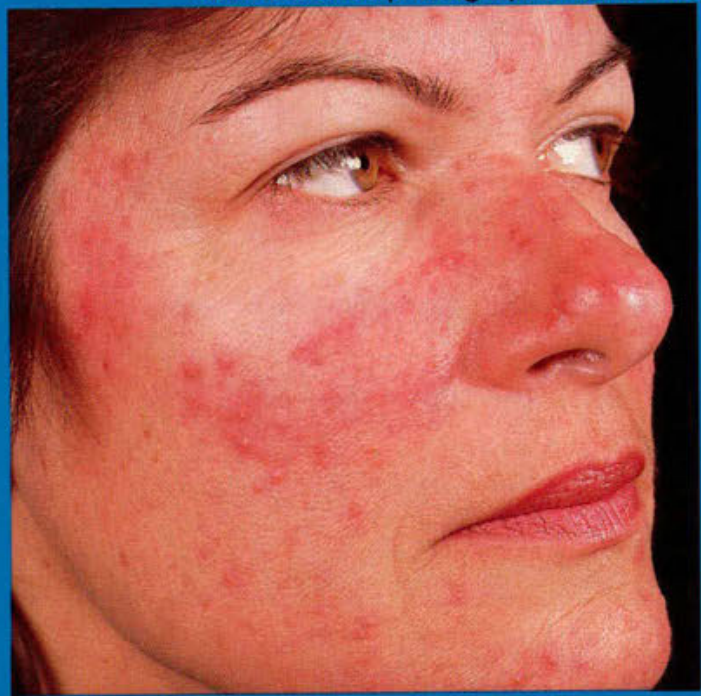

Baseline

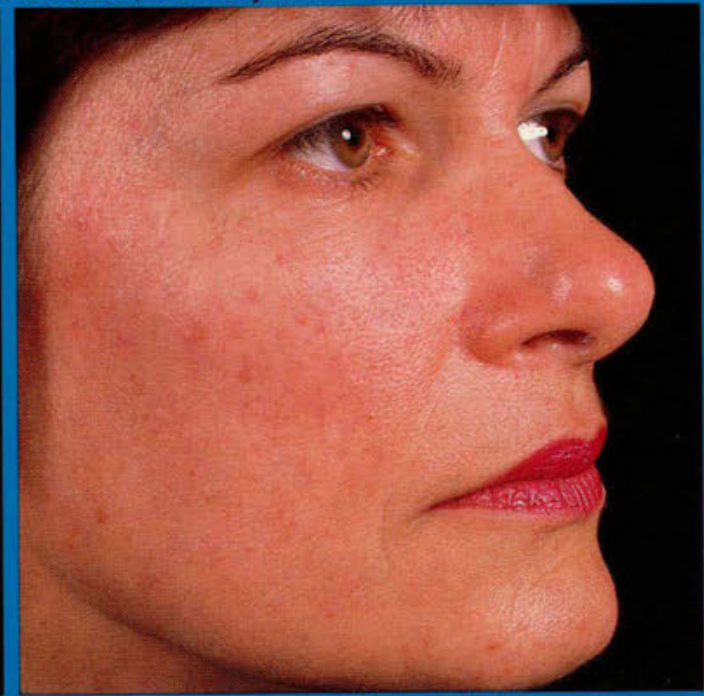

After 9 Weeks of MetroGel Therapy

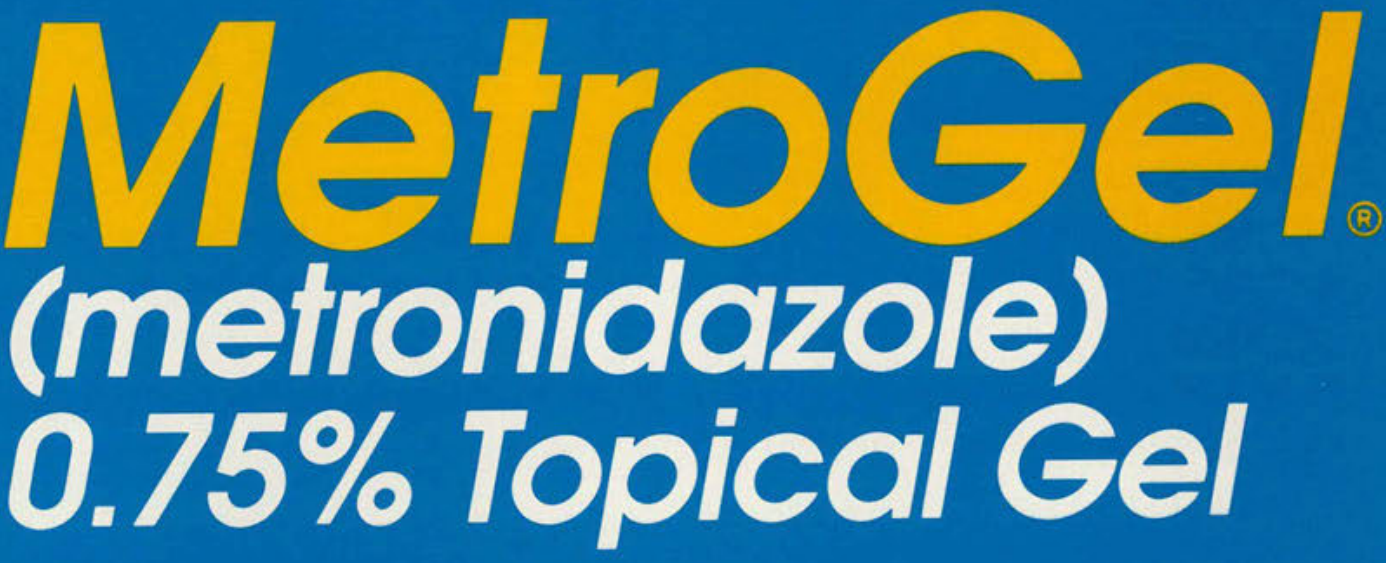

PROVEN EFFECTIVE ${ }^{2,3,4}$

Significant reduction of papules, pustules and erythema in over $70 \%$ of moderate to severe rosacea patients after nine weeks Continuing improvement through nine weeks of treatment

FORMULATED FOR PATIENT ACCEPTANCE

Elegant gel is $95 \%$ water and contains no oils, alcohols or fragrances

- Can be used under make-up, sunscreens or moisturizers

\section{EXCELLENT SAFETY PROFILE}

No reports of systemic side effects

- Avoids common problems associated with oral tetracyclines such as

GI distress and vaginal candidiasis

\section{CONVENIENT BID DOSING}

Apply a thin film of MetroGel morning and evening 


\section{NOW'\#1 THERAPY FOR ROSACEA}

Un-retouched photographs from clinical studies, courtesy Arthur Sober, M.D.

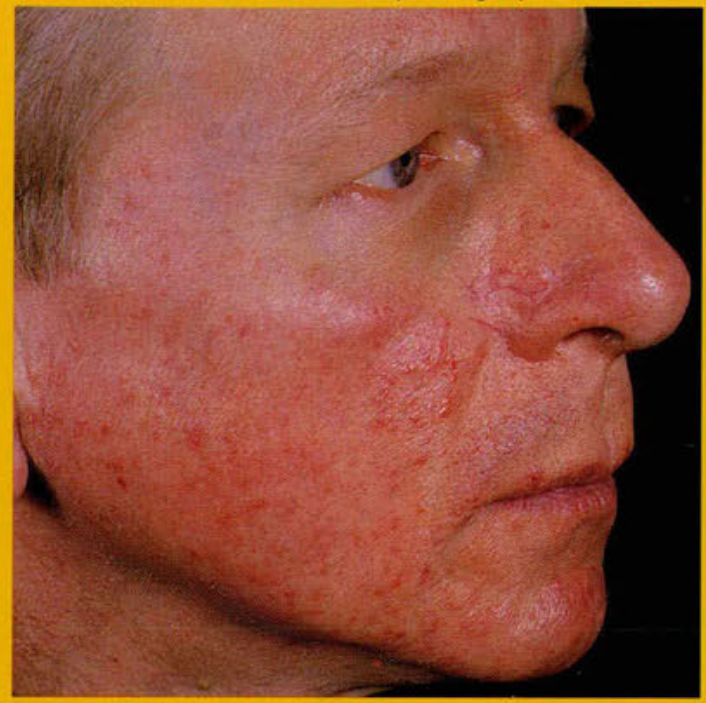

Baseline

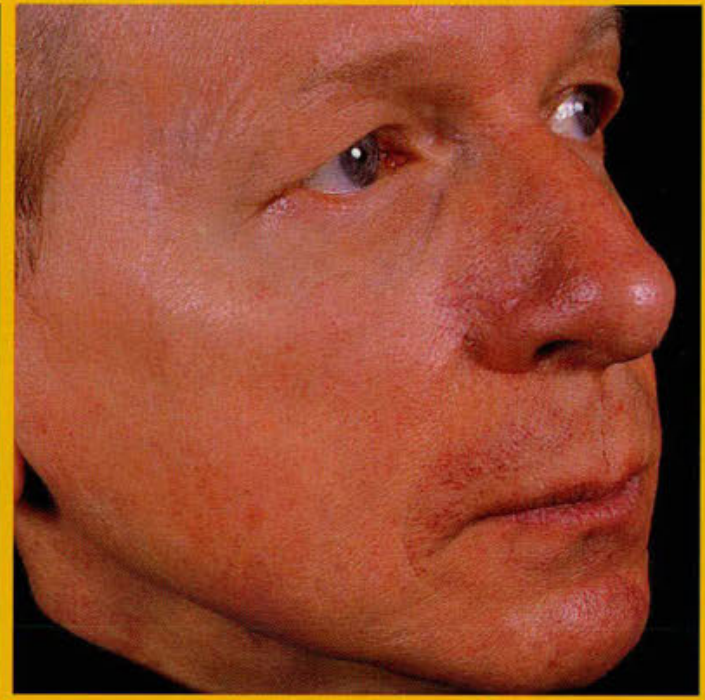

After 9 Weeks of MetroGel Therapy

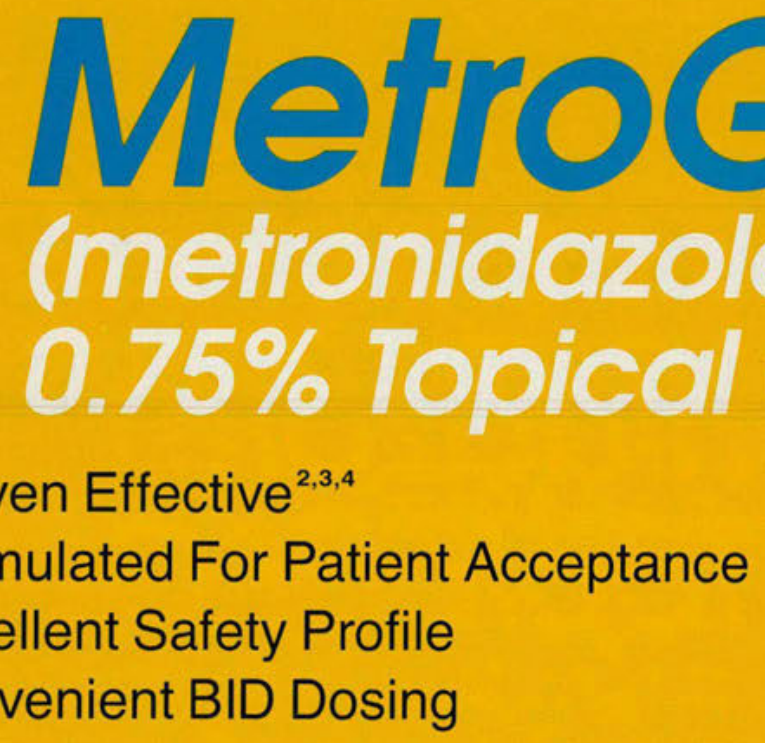

(B)

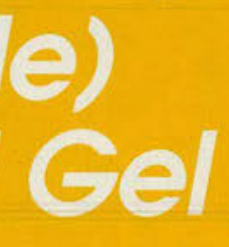

- Proven Effective $e^{2,3,4}$

- Formulated For Patient Acceptance

- Excellent Safety Profile

- Convenient BID Dosing

Brief Summary

MetroGel

(metronidazole) $0.75 \%$ Topical Gel

FOR TOPICAL USE ONLY

(NOT FOR OPHTHALMIC USE)

CLINICAL PHARMACOLOGY The mechanisms by which METROGEL. acts in reducing inflammatory lesions of rosacea are unknown, but may include an anti-bacterial andior an anti-inflammatory effect.

INDICATIONS AND USAGE METROGEL is indicated for topical application in the treatment of inflammatory papules, pustules, and erythema of rosacea.

CONTRAINDICATIONS METROGEL is contraindicated in individuals with a history of hypersensitivity to metronidazole, parabens, or other ingre. dients of the formulation

PRECAUTIONS Because of the minimal absorption of metronidazole and consequently its insignificant plasma concentration after topical adminis. tration, the adverse experiences reported with the oral form of the drug have not been reported with METROGEL

General METROGEL has been reported to cause tearing of the eyes. Therefore, contact with the eyes should be avoided. If a reaction suggesting local imtation occurs, patients should be directed to use the medication less Irequently, discontinue use temporarily, or discontinue use until further instructions. Metronidazole is a nitroimidazole and should be used with care in patients with evidence of, or history of, blood dyscrasia.

Drug Interactions Drug interactions are less likely with topical administra tion but should be kept in mind when METROGEL is prescribed for patients who are receiving anticoagulant treatment. Oral metronidazole has been reported to potentiate the anticoagulant effect of coumarin and wartarin resulting in a prolongation of prothrombin time.

Carcinogenesis: Tumorigenicity in Rodents Metronidazole has show evidence of carcinogenic activity in a number of studies involving chronic, ora administration in mice and rats but not in studies involving hamsters. These studies have not been conducted with $0.75 \%$ metronidazole gel, which would result in significantly lower systemic blood levels than oral formulations.

Mutagenicity Studies Although metronidazole has shown mutagenic activity in a number of in vitro bacterial assay systems, studies in mammals (in vivo) have falled to demonstrate a potential for genetic damage

Pregnancy This drug should be used during pregnancy only it clearly needed.

Nursing Mothers Even though METROGEL blood levels are significantly lower than those achieved atter oral metronidazole, a decision should be made whether to discontinue nursing or to discontinue the drug. taking into account the importance of the drug to the mother.

Pediatric Use Safety and effectiveness in children have not been established.

ADVERSE REACTIONS Adverse conditions reported include watery (tearing) eyes if the gel is applied too closely to this area, transient redness and mild dryness, burning, and skin irritation. None of the side effects exceeded an incidence of $2 \%$ of patients.

DOSAGE AND ADMINISTRATION Apply and rub in a thin film of METROGEL twice dally, morning and evening, to entire affected areas after washing. Significant therapeutic results should be noticed within three weeks. Clinical studies have demonstrated continuing improvement through nine weeks of therapy
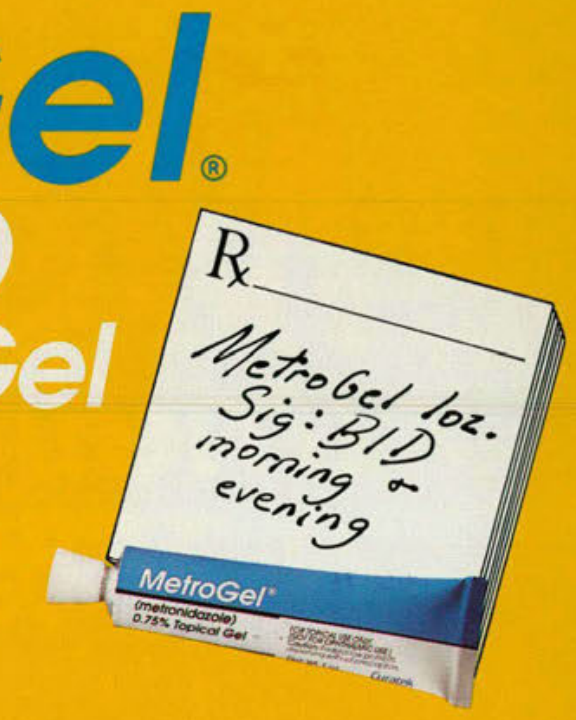
Table 2

Immunochemistry Analyzers for the Physician's Office Laboratory

\begin{tabular}{|c|c|c|c|c|}
\hline Manufacturer & Model & Type & Comments & Cost \\
\hline \multirow[t]{2}{*}{$\begin{array}{l}\text { Abbott Laboratories } \\
\text { Diagnostics Division } \\
\text { Abbott Park 605th D-49B } \\
\text { Abbott Park, IL 60064 } \\
1(800) 323-9100\end{array}$} & IMx & Bench-top & $\begin{array}{l}\text { Proprietary reagents } \\
\text { Batch analyzer } \\
\text { Variable throughput } \\
12+\text { assays }\end{array}$ & $\$ 40,000^{*}$ \\
\hline & TDx & Bench-top & $\begin{array}{l}\text { Proprietary reagents } \\
\text { Batch analyzer } \\
\text { Variable throughput }\end{array}$ & $\$ 40,000^{*}$ \\
\hline $\begin{array}{l}\text { Behring Diagnostics Inc } \\
17 \text { Chubb Way } \\
\text { Somerville, NJ } 08876 \\
1(800) 854-9256\end{array}$ & TurbiTime & Bench-top & $\begin{array}{l}\text { Proprietary reagents } \\
\text { Manual sample input } \\
45 \text { to } 60 \text { seconds per } \\
\text { assay }\end{array}$ & $\$ 20,000^{*}$ \\
\hline \multirow[t]{2}{*}{$\begin{array}{l}\text { Hybritech Incorporated } \\
11095 \text { Torreyana Rd } \\
\text { San Diego, CA } 92121 \\
1(800) 854-1957\end{array}$} & Tandem Icon & Portable & $\begin{array}{l}\text { Proprietary reagents } \\
\text { Manual sample input } \\
\text { Hemoglobin, creatine } \\
\text { kinase-myocardial } \\
\text { band only } \\
\text { Variable throughput }\end{array}$ & $\$ 2,000$ \\
\hline & Photon II & Bench-top & $\begin{array}{l}\text { Proprietary reagents } \\
\text { Manual sample input } \\
13 \text { assays available } \\
\text { Variable throughput }\end{array}$ & $\$ 7,500$ \\
\hline $\begin{array}{l}\text { PB Diagnostics } \\
151 \text { University Ave } \\
\text { Westwood, MA 02090 } \\
1(800) 321-3394\end{array}$ & Opus & Bench-top & $\begin{array}{l}\text { Proprietary reagents } \\
\text { Automated operation } \\
10+\text { assays available } \\
20 \text { to } 60 \text { assays per hour }\end{array}$ & $\$ 35,000^{*}$ \\
\hline
\end{tabular}

by using a fluorescent ELISA. In this assay, the analyte in the patient's sample binds to a specific unlabeled antibody that is bound to a solid support in the reaction container. A second antibody conjugated to an enzyme is then added to the mixture of the analyte and unlabeled antibody, forming a sandwich complex that remains intact when the sample container is washed with reagents. Substrate is then added to the bound antibody/analyte/antibodyenzyme complex, which then reacts to produce fluorescence that is proportional to the concentration of analyte in the patient's sample.

The Behring Turbitime uses turbidimetry to measure the concentration of analytes in the patient's specimens. Turbidimetry is used to quantify analytes by measuring the ratio of the intensity of transmitted light to the intensity of incident light that passes through a dispersion of analyte (antigens) and antibodies. Quantification of an unknown is affected by light absorbed by solvent and particles, as well as by light scattered by antigen-antibody complexes. Immunochemistry analyzers are also microprocessor-controlled.

Small analyzers, such as the Turbitime analyzer, require the operator to manually pipette the sample and the reagent. Midsize immunochemistry analyzers, such as the TDx and IMx (Abbott) and the Opus immunoassay systems, have automated sample and reagent handling. Immunochemistry analyzers generally use proprietary reagents.

The major differences among immunochemistry analyzers is the size of the instrument's test menu. For example, the Turbitime offers a menu of specific proteins that includes immunoglobulins, transferrin, haptoglobin, and 
apolipoproteins. The Opus menu focuses on therapeutic drug monitoring (eg, digoxin, theophylline, and valproic acid), hormone assays (eg, human chorionic gonadotropin, thyroidstimulating hormone), and tests for infectious diseases (eg, anti-human immunodeficiency virus and hepatitis B surface antigen). The TDx has a menu of therapeutic drugs (eg, acetaminophen, digoxin, theophylline), hormone (eg, thyroid function tests, cortisol), and specific protein assays (eg, immunoglobulins, transferrin). The IMx has a menu of metabolic disease (eg, $\alpha$-fetoprotein), tumor marker (carcinoembryonic antigen), and infectious disease assays (hepatitis virus assays).

The degree of sophistication of immunochemistry analyzers parallels that of other chemistry analyzers, although all have microprocessor control. The smaller instruments require manual manipulation of the specimen and reagent. Furthermore, the degree of data reduction is significantly less on the smaller instruments, generally consisting of little more than printing the test name, patient identification number, test result, and unit of measure.

The cost of immunochemical analyzers ranges from $\$ 20,000$ to $\$ 40,000$, but these analyzers can also be obtained through a reagent rental agreement whereby the physician agrees to purchase a specified volume of the reagents from the manufacturer in exchange for the use of the instrument.

\section{Cell counters}

Hematology cell-counting instruments marketed specifically to POLs are bench-top instruments that use electrical impedance to count cells (erythrocytes, leukocytes, or platelets). Table 3 provides the names and addresses of manufacturers of cell counters, representative models, and a brief description of the models.

Blood, diluted with saline solution, is aspirated into the instrument and drawn through a narrow aperture as an electric current flows through the aperture. The saline solution is an electrolyte and allows electric current to flow. However, the cells are poor conductors of the electric current, and subsequently im- pede its flow. The degree of automation varies among cell counters. The basic instruments require the operator to manually dilute the blood before it is aspirated into the instrument. These less sophisticated analyzers provide limited hematologic data, such as basic cell counts (red blood cell [RBC], white blood cell [WBCs], and platelet counts) and hemoglobin quantification. However, the more sophisticated instruments automatically dilute the blood specimens and provide cell counts, $\mathrm{RBC}$ indices, and frequently a three-part differential count that includes an enumeration and percentage of granulocyte, lymphocyte, and monocyte populations.

The list prices of cell counters range from approximately $\$ 15,000$ for the basic instruments to approximately $\$ 30,000$ for analyzers that can enumerate cells, produce $\mathrm{RBC}$ indices, and provide a three-part differential cell count.

\section{Selection criteria, cost considerations, and needs analysis}

When physicians decide to have an office laboratory, they must determine the types of laboratory tests that will be offered and the volume of those tests that will be done each year. These data form the basis on which they can select the instruments that optimally meet the needs of the laboratory. Many factors-some based on needs, others on intangible factorshave to be considered before acquisition of the instruments.

Most currently available instruments perform adequately and provide similar basic functions. To compound the difficulties of selection, no two instruments within any given class are identical. No two small chemistry analyzers offer exactly the same tests or features. This is true of immunochemistry analyzers and cell counters as well. Knowing this situation, physicians must then determine which instruments will perform optimally in the POL, match the POL's test mix, and meet the capabilities of the person who will ultimately operate the instrument.

Needs can be analyzed by carefully observing the laboratory's daily operation and by taking into consideration the operational flexibil- 
Table 3

Cell Counters for the Physician's Office Laboratory

\begin{tabular}{|c|c|c|c|c|}
\hline Manufacturer & Model & Type & Comments & Cost \\
\hline \multirow[t]{2}{*}{$\begin{array}{l}\text { Coulter Electronics, Inc } \\
\text { PO Box 2145 } \\
\text { Hialeah, FL } 33012 \\
1(800) 327-6531\end{array}$} & T Series & Bench-top & $\begin{array}{l}\text { Automatic sample dilution } \\
\text { Basic cell counts plus } \\
\text { lymphocyte count }\end{array}$ & $\$ 16,000^{*}$ \\
\hline & CBC5 & Bench-top & $\begin{array}{l}\text { Manual sample dilution } \\
\text { Counts red blood cells, white } \\
\text { blood cells; determines } \\
\text { hemoglobin level, hemato- } \\
\text { crit, and mean corpuscular } \\
\text { volume }\end{array}$ & $\$ 16,000^{*}$ \\
\hline $\begin{array}{l}\text { Miles Inc } \\
\text { Diagnostics Division } \\
\text { PO Box } 70 \\
\text { Elkhart, IN } 46515 \\
1(800) 248-2637\end{array}$ & $\begin{array}{l}\text { Clinicount } \\
\text { Hematology } \\
\text { System }\end{array}$ & Bench-top & $\begin{array}{l}\text { Manual sample dilution } \\
\text { Counts red blood cells, white } \\
\text { blood cells; determines } \\
\text { hemoglobin level, hemato- } \\
\text { crit, mean corpuscular } \\
\text { volume, mean corpuscular } \\
\text { hemoglobin, mean corpus- } \\
\text { cular hemoglobin } \\
\text { concentration }\end{array}$ & $\$ 16,000^{*}$ \\
\hline $\begin{array}{l}\text { Roche Diagnostic Systems, Inc } \\
\text { Subsidiary of Hoffman- } \\
\text { La Roche, Inc } \\
\text { Montclair, NJ } 07042 \\
1 \text { (800) 526-1247 }\end{array}$ & $\begin{array}{l}\text { Cobas Minos } \\
\text { Series }\end{array}$ & Bench-top & $\begin{array}{l}\text { Automatic sample dilution } \\
8 \text { to } 18 \text { parameters that vary } \\
\text { with model } \\
60 \text { samples per hour }\end{array}$ & $\begin{array}{l}\$ 17,000 \\
\text { to } \\
\$ 55,000\end{array}$ \\
\hline $\begin{array}{l}\text { Serono Baker Diagnostics } \\
100 \text { Cascade Dr } \\
\text { Allentown, PA } 18103 \\
1 \text { (215) } 264-2800\end{array}$ & $\begin{array}{l}\text { System } 9000 \\
\text { Cell Counters }\end{array}$ & Bench-top & $\begin{array}{l}\text { Automatic sample dilution } \\
8 \text { parameters (red cell distri- } \\
\text { bution width and } \\
\text { 3-part differential } \\
\text { available) } \\
60 \text { samples per hour }\end{array}$ & $\begin{array}{l}\$ 25,000 \\
\text { to } \\
\$ 55,000\end{array}$ \\
\hline
\end{tabular}

ity of the instrument, the laboratory services that the POL can provide, and the cost of the instrument, labor, reagents, and other supplies. The volume of tests must be assessed to determine the size of the instrument to acquire. If the instrument is too slow for the volume of testing, the desired patient benefits of faster test turnaround and rapid initiation of therapy will not be met. However, a highthroughput analyzer offers little to the physician if there is insufficient test volume to allow for optimal instrument use. Then, the instrument may become a liability because of the overhead required to employ a dedicated operator and to maintain an underused instrument.
Vendors offer options for acquisition of instruments. These options range from direct purchase to lease and reagent rental plans. In the reagent rental plan, the physician agrees to pay a set price for reagents, and in return the vendor provides the instrument. Some rental plans demand the purchase of a set volume of reagents per year at an established cost. However, if the laboratory test volume falls short of the contracted volume, the physician is responsible for the purchase of the unused reagents. If this situation occurs, the estimated cost per test may increase by as much as $50 \%$, leaving a considerably smaller margin than originally anticipated.

Finally, a necessary consideration in the ac- 
quisition of laboratory instruments is the skill level required of the operator. Operators can proficiently test specimens on small benchtop chemistry analyzers after a minimum of on-site training by the vendor. Small benchtop chemistry analyzers can be conveniently and comfortably used by medical assistants and nurses. However, more sophisticated instruments require a dedicated operator with more specialized training. Operators of larger chemistry analyzers like the Abbott Spectrum must attend a week-long training session at the manufacturer's training center.

Well-trained instrument operators perform analyses at a significantly higher skill level than do untrained or undertrained operators. ${ }^{1}$ Therefore, the physician must include into the instrument selection criteria the feasibility of the added expense of having trained, dedicated instrument operators.

\section{Summary}

Having a POL can be a valuable asset for the physician. Careful consideration must go into the selection of laboratory instruments. One-toone comparisons of instruments are difficult because no two instruments are identical. Therefore, the physician must establish what test menu is required, estimate the desired test throughput for the POL, contact instrument vendors to obtain information on desired instruments, and evaluate financial plans for acquisition.

Prior to acquiring any instrument, the physician should obtain the names of at least three users of the device under consideration. During conversations with the users, it is recommended that the instrument's reliability, its true speed and accuracy in reporting test results, actual maintenance requirements, ease of operation, and any additional costs incurred during installation and operation be thoroughly evaluated.

The physician may wish to have the assistance of a financial planner or laboratory consultant during the acquisition process. The modest fees charged by the experts are good assurance when compared with the expense of an inappropriate instrument selection.

\footnotetext{
1. Nanji AA, Poon R, Hinberg I: Quality of laboratory test results obtained by non-technical personnel in a decentralized setting. AJCP 1988;89:797-801.

Addison LM, Fischer PM: The Office Laboratory, ed 2.East Norwalk, Conn, Appleton \& Lange, 1989.

Lifshitz MS, DeCresce RP: Understanding, Selecting, and Acquiring Clinical Laboratory Analyzers. New York, Alan R Liss, Inc, 1986.

Yarrison G: Physicians' office laboratories: Support services and revenue options. Lab Med 1988;19:171-173.
} 


\section{HOTELS REQUIRE RESERVATIONS PRIOR TO SEPTEMBER 27, 1991}

egistration, exhibits and didactic sessions will be held at the New Orleans Convention Center. AOA planned social functions will be eld at the New Orleans Hilton Riverside and Towers. The official hotels are the Hilton Riverside \& Towers, Holiday Inn Crowne Plaza, lyatt Regency New Orleans and the Sheraton New Orleans Hotel. Accommodations may be requested at any hotel; however, the ocial functions of the following groups have been assigned as indicated: (AOA Shuttle Bus Service will be provided between the otels and the Convention Center)

articipating Groups:

merican Academy of Osteopathy New Orleans Hilton Riverside \& Towers merican Osteopathic Academy of Addictionology. merican Osteopathic College of Allergy and Immunology. merican Osteopathic College of Dermatology. ..(No hotel-based functions) Hyatt Regency New Orleans merican College of Osteopathic Emergency Physicians Sheraton New Orleans Hotel merican College of General Practitioners in Osteopathic Medicine and Surgery merican College of Neuropsychiatrists. merican Osteopathic College of Pathologists. merican Osteopathic College of Preventive Medicine merican Osteopathic College of Rehabilitation Medicine. Imerican Osteopathic College of Rheumatology, Inc. Imerican Osteopathic Academy of Sclerotherapy, Inc. Iuxiliary to the American Osteopathic Association 3esearch Conference. New Orleans Hilton Riverside \& Towers Hyatt Regency New Orleans Sheraton New Orleans Hotel Sheraton New Orleans Hotel ..(local restaurant) (No hotel-based functions) (No hotel-based functions) New Orleans Hilton Riverside \& Towers ..New Orleans Hilton Riverside \& Towers The Association of Osteopathic State Executive Directors and the National Association of Osteopathic Foundations also meet in conunction with the AOA Convention)

Please indicate your preferred hotel (check one) and mail this form to:

AOA HOUSING BUREAU

1520 SUGAR BOWL DRIVE

NEW ORLEANS, LOUISIANA 70112

NDICATE THREE CHOICES BY WRITING 1, 2, OR 3 IN THE APPROPRIATE BOXES (PREFERENCE BEING \#1)

NEW ORLEANS HILTON RIVERSIDE \& TOWERS \#2 Poydras

New Orleans, LA 70140

(504) $561-0500$

Single/Double

Standard

Suites

Two Bedroom

\section{Executive Towers} $\$ 155 \quad \$ 185$ $\$ 635$ \& Up

\section{HYATT REGENCY NEW ORLEANS}

At Louisiana Superdome

Poydras at Loyola Avenue

New Orleans, LA 70140

(504) 561-1234

Single/Double $\$ 124$

Suites: SEMI $\$ 275$ \& Up

One Bedroom $\$ 350$ \& Up

Two Bedroom

\section{HOLIDAY INN CROWNE PLAZA}

333 Poydras Street

New Orleans, LA 70130

(504) 525-9444

Single/Double $\$ 110$

Suites: One Bedroom Two Bedroom
$\$ 298$ \& Up $\$ 448$ \& Up
SHERATON NEW ORLEANS HOTEL

500 Canal Street

New Orleans, LA 70130

(504) $525-2500$

Single/Double. $\$ 125$

Suites: One Bedroom. $\$ 250$ \& Up Two Bedroom. 


\section{IMPORTANT INFORMATION}

1. Please complete this form in detail and mail it to the AOA HOUSING BUREAU, 1520 SUGAR BOWL DRIVE, NEW ORLEANS, LOUISIANA 70112 - WITH REQUIRED DEPOSIT.

2. Do NOT send your reservations to the American Osteopathic Association's Central Office or to the hotel - all hotel reservations must be made using this form.

3. Check out time is 12:00 Noon, therefore, rooms may not be available until 3:00 p.m.

4. All reservations will be processed on a first-come, first-served basis and must be received by the AOA HOUSING BUREAU by September 27, 1991. You will receive an acknowledgment from the Housing Bureau and a confirmation from the hotel.

5. A deposit for first night's occupancy should be sent to the AOA HOUSING BUREAU. Make checks payable to the AOA HOUSING BUREAU or complete the credit card information on the bottom of this form.

6. Please complete this form in detail. Incomplete forms will delay room assignments.

7. The hotel must be notified in writing of any room cancellations at least 72 hours in advance.

8. Registration, exhibits and didactic sessions will be held at the New Orleans Convention Center.

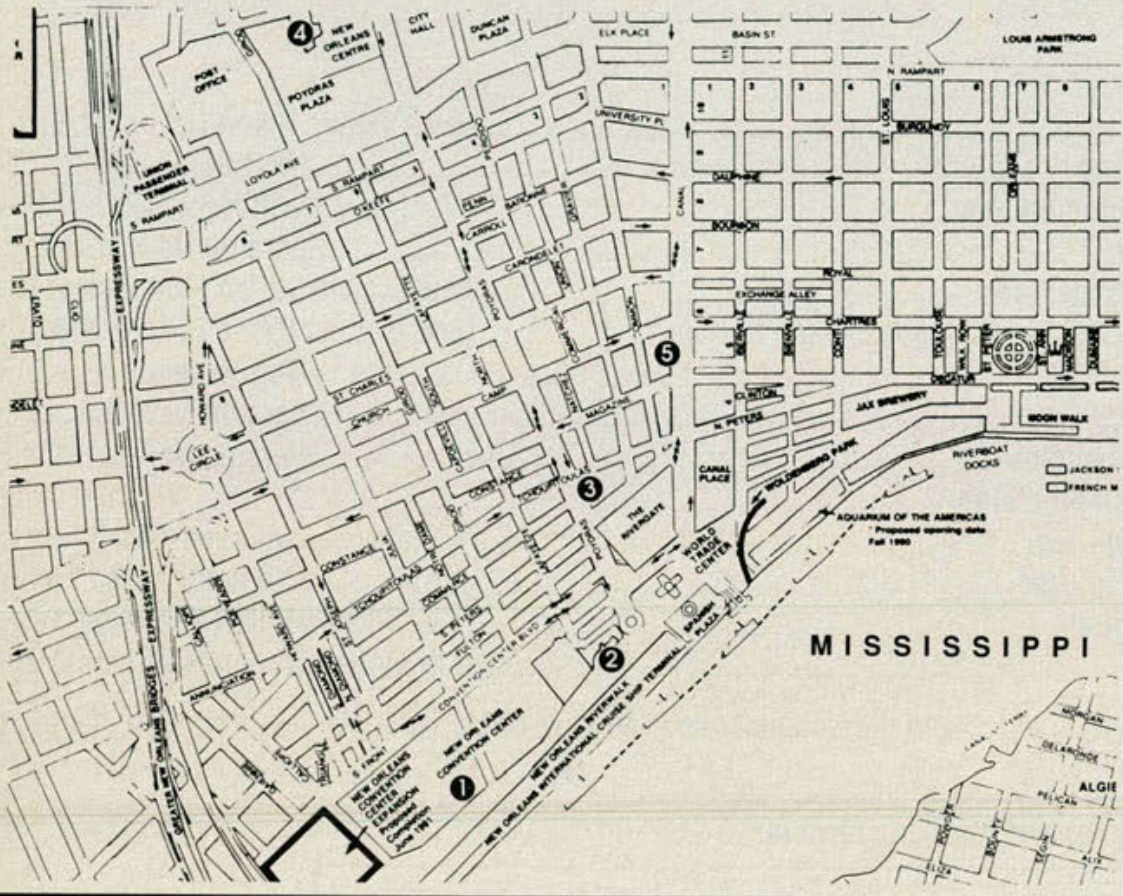

\section{New Orleans Convention Center}

2. New Orleans Hilton Riverside and Towers

3. Holiday Inn Crowne Plaza

4. Hyatt Regency New Orleans

5. Sheraton New Orleans Hotel

HOTEL CHOICES: (1)

(2)

(3)

TYPE OF ACCOMMODATION: (please check one) SINGLE $\square \quad$ DOUBLE $\square$ TWIN SUITES: 1 BEDROOM $\square \quad 2$ BEDROOM

OTHER:

ARRIVAL DATE:

DEPARTURE DATE:
NAME OF ALL OCCUPANTS OF ROOM(S): (please print)

1.

2.

3.

APPROX. TIME AM/PM

APPROX. TIME

SEND CONFIRMATION TO: (please print)

NAME:

ADDRESS:

CITY:

STATE: ZIP CODE:

TELEPHONE (Area Code):

\section{CREDIT CARD AUTHORIZATION}

The AOA Housing Bureau and assigned hotel are authorized to use this information to assess a deposit for my hotel room reservation. This deposit is not refundable unless reservations are canceled 72 hours prior to arrival. 